band of rainfall) migrated southward. In summing up these effects, it is not clear whether increased methane emissions south of the Equator, most probably from southern South America, could have counterbalanced the loss of northerly emissions. If not, an alternative source of methane is required to explain the observed minimum in atmospheric levels of the gas 5,000 years ago. Other natural sources, like growing river deltas in the later Holocene $e^{6}$ have been proposed, but human action is at least one possibility.

The evolution of carbon dioxide concentrations over the past 8,000 years can be simulated with carbon-cycle models without resorting to early human emissions (Victor Brovkin, Max Planck Institute for Meteorology, Germany), as suggested previously based on isotopic data ${ }^{7}$. Furthermore, it seems difficult to generate sufficiently large carbon dioxide changes to explain the observations based solely on human-induced variations in land cover during the Holocene (J. Pongratz, Max Planck Research School on Earth System Modelling, Germany and T. Hickler, Lund University, Sweden ${ }^{8}$ ), or by biomass burning (J. Marlon, University of Oregon, $\mathrm{USA}^{9}$ ).

Opinions are divided on the question of whether the Earth would now be entering another glacial period were it not for the human activities that started several millennia ago, as Ruddiman suggests. S. Vavrus (University of Wisconsin, USA) presented simulations with a general circulation model based on an assumption of what the natural levels of atmospheric carbon dioxide and methane should be today, and concluded that glacial inception would have been likely. However, Michel Crucifix (Université catholique de Louvain, Belgium) - using a statistical model of ice ages linking ice volume and carbon dioxide - concluded that the absence of glacial inception before 50,000 years in the future remains the most likely scenario when palaeoclimate data are taken into account.

Ruddiman's hypothesis of a detectable early human impact on greenhouse-gas levels, and hence climate, challenges us to grapple with the full spectrum of processes controlling climate and biogeochemistry, as well as the fascinating and poorly known history of early human civilizations. Much work lies ahead, for example, on more detailed climate reconstructions from the monsoon region (X. Zhou, Chinese Academy of Sciences, China) and towards a better understanding and modelling of the late-Holocene land-use history of the Americas and Europe (R. Nevle, Bellarmine College Preparatory, USA, H. Manstein, Deutsches Zentrum für Luft- und Raumfahrt, Germany and J. Kaplan, Ecole Polytechnique Fédérale de Lausanne, Switzerland).
As Neil Roberts (University of Plymouth, UK) suggested at the meeting, the distinction between a world dominated by humans after AD 1750 and a natural climate state before that date may indeed not be a useful dichotomy, as humans clearly have been modifying their environment for longer than 250 years. However, whether or not humans started warming up the planet before AD 1750, today's emissions of greenhouse gases are significant, and so are the challenges of future climate change.

\section{Edward J. Brook is at the Department of Geosciences, Oregon State University, Corvallis, Oregon 97330, USA. \\ e-mail: brooke@geo.oregonstate.edu}

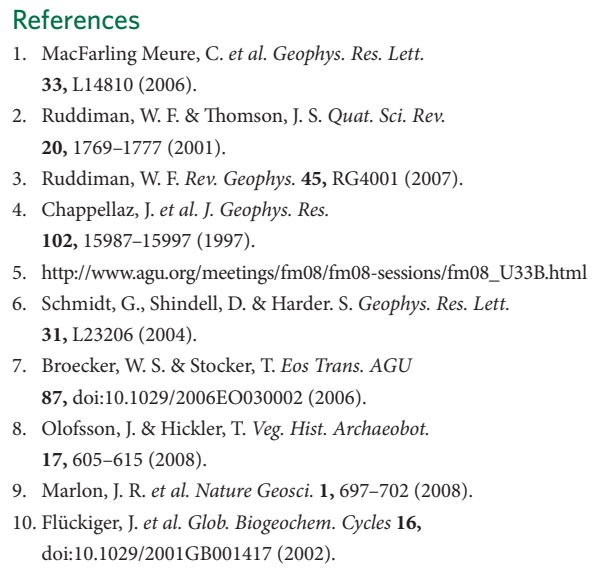

ERRATUM

\title{
Mercury methylation made easy
}

\section{Richard Sparling}

Nature Geoscience 2, 92-93 (2009); published online: 30 January 2009; corrected after print: 30 January 2009.

In the print version of this News \& Views the page numbers given in the text and reference 1 were incorrect; the correct range is $123-126$. These errors have been corrected in the HTML and PDF versions. 